ORIGINAL ARTICLE

\title{
Effects of varied packages of plyometric training on selected motor ability components among university students
}

\author{
Wasim Khan ${ }^{1 \mathrm{ABCDE}}$, Taslem Arif ${ }^{2 \mathrm{ACD}}$, Khushdil K. Muhammad ${ }^{1 \mathrm{CD}}$, Sardar N. Sohail ${ }^{1 \mathrm{D}}$, Irina V. Kriventsova ${ }^{3 \mathrm{DE}}$ \\ ${ }^{1}$ Gomal University, D.I.Khan, Pakistan \\ ${ }^{2}$ Sarhad University of Information Technology, Pakistan \\ ${ }^{3}$ H.S. Skovoroda Kharkiv National Pedagogical University, Ukraine
}

Authors' Contribution: A - Study design; B - Data collection; C - Statistical analysis; D - Manuscript Preparation; E - Funds Collection.

\begin{abstract}
Purpose: $\quad$ The main focus of the study was to examine the effect of varied packages of plyometric training on speed, leg explosive power, and muscular endurance among university students.

Material: $\quad$ Sixty students (age $=21.37+1.40$ ) were divided into two groups namely, Control Group $(C G, n=15)$ and Experimental Group ( $E G, n=45$ ). The $E G$ was further divided into three different groups based on the different training packages such as Low, Medium, and High-Intensity plyometric training. The .05 level of confidence was fixed as the level of significance to test the ' $F$ ' ratio obtained by the analysis of covariance, which was considered as appropriate. Plyometric training for a period of eight weeks offered to the participants of the Experimental Group.

Results: $\quad$ The results revealed that various plyometric training programs have produced significant development in improving motor ability components such as speed, leg explosive power, and muscular endurance of the participants $(p<.05)$. The results indicated that high-intensity plyometric training was noticed as superior then low and medium intensity plyometric training in the perspective of the effect of varied packages of plyometric on selected motor ability components among participants.

Conclusions: Keeping in view the utility and importance of plyometric training, we recommended that the exercise protocol used in this study may helpful for the development and improvement of such components to get peak performance in sports.

Keywords: $\quad$ effect, varied packages, speed, muscular endurance, leg explosive power
\end{abstract}

\section{Operational Definitions of the Terms:}

Plyometric Training: Plyometric training refers to exercise that enables a muscle to reach maximal strength in a short time as possible.

Speed: Speed is generally defined as quickness. In the field of physical education and sports, the term speed refers to the quick action of the limbs.

Explosive Leg Power: A maximum or near maximum power output in the shortest possible is called.

Muscular Endurance: Muscle endurance is the ability of a muscle or group of muscles to exert force for a longer duration.

\section{Introduction}

Sports training is a planned and controlled process aimed to promote motor performance as well as to positively change the behavior of a person [1]. For the positive outcome of training, it is considered important to perform the training according to its principles [2].

The importance of sports training can be assessed by the fact that all other kinds of facilities provided to athletes may prove to be futile if the athletes are not provided with effective sports training. Without proper sports training, one cannot achieve or fulfill his/her potentials [3]. Comprehensive sport training has paramount significance in producing peak performance in sport [4].

(c) Wasim Khan, Taslem Arif, Khushdil K. Muhammad, Sardar N. Sohail, Irina V. Kriventsova, 2020

doi:10.15561/20755279.2020.0504
Sedaghati [5] single out that body adaptations and the high level of achievement in different sporting fields depend on the degree of fitness and training. Among the numerous types of available exercises, plyometrics assist in the development of power, a foundation from which the athlete can refine the skills of their sport [6].

Regular participation in plyometric training is considered important for improving the standard of muscular endurance [7]. According to researchers [8], plyometric training is basically done for improving the endurance of muscle as well as adopting of muscles. Plyometric is not inherently dangerous, but the highly focused and intense movements used in repetition may increase the potential level of stress on joints, muscles, and tendons units [9].

El-Ashker et al. [10] assessed the impact of 8-weeks plyometric training program on the sprint and jump performance. The authors defined the plyometric training can be recommended to athletics coaches as an additional training alternative to improve sprint and long jump abilities in athletes.

Golzari et al [11] compared the impact of 6-weeks strength and plyometric exercises on some of the kinematic parameters of the lower extremities in the impact on female football players aged 20 to 25 years. The findings show that 6-week strength and plyometric exercises can significantly improve the speed parameters of the ball, the angular velocity of the knee joint and the angular velocity of the hip in the impact performance on 
the foot of female soccer players.

The other investigations defined that:

- Specific stretching exercises combined with plyometrics may be more beneficial than other training strategies in young sprint-hurdlers [12];

- The use of progressive plyometric exercise on an unstable surface shows an improvement in the results of the functional movement screening test and movement performance [5].

A proper progression and detailed program planning should be utilized when implementing plyometric exercises due to their different impact kinetics and how they might influence the body upon ground contact [13].

Plyometric preparation adds to change in upright hop execution, quickening, leg quality, strong power, the increment of joint mindfulness, and in general game particular aptitudes [14].

However, little scientific information is currently available to determine whether plyometric training truly boosts skill performance in individuals [15].

Different training methods are used to develop physical fitness components. Each method aims to develop one or the other components. The selection of the method depends upon the period of training, level of athlete, age, and sex of athletes. The selection of the correct training method is very much important for the type of training being offered to the athletes. This particular study focused to examine the effect of varied packages of plyometric training on speed, leg explosive power, and muscular endurance among untrained university students.

\section{Research Hypotheses}

Based on available data its was hypothesized that:

HA 1. There is a significant effect of varied packages of plyometric training on speed.

HA 2. There are significant mean differences in the effects of varied packages of plyometric training on speed.

HA 3. There is a significant effect of varied packages of plyometric training on leg explosive power.

HA 4. There are significant mean differences in the effects of varied packages of plyometric training on leg explosive power.

HA 5. There is a significant effect of varied packages of plyometric training on muscular endurance.

HA 6. There are significant mean differences in the effects of varied packages of plyometric training on muscular endurance.

\section{Material and Methods}

\section{Participants}

The participants of this research comprised of Sixty $(n=60)$ healthy undergraduate university male students of Gomal University, Dera Ismail Khan. The students $($ age $=21.37+1.40)$ were divided into two groups namely, Control Group (CG, $\mathrm{n}=15)$ and Experimental Group (EG, $\mathrm{n}=45$ ). The $\mathrm{EG}$ was further divided into three different groups based on the different training packages such as Low, Medium, and High-Intensity plyometric training. Plyometric training for a period of eight weeks offered to the participants of the Experimental Group.

\section{Inclusion Criteria}

The subjects included in the study by adopting the following inclusion criteria:

1. All male students included in the study;

2. The healthy student included in the study;

3. The student aging 20-23 years included in the study.

The study was conducted in accordance with The Code of Ethics of the World Medical Association (Declaration of Helsinki).

Research Design

The study contains a single-dimensional design consisted of four portions by giving various sets of exercise. In order to assist the investigation, sixty unskilled healthy undergraduate university male students at the age of 20 to 23 were selected as subjects through random sampling. The subjects of the study distributed into four equal groups namely Experimental Group (EG) A. (First Package of Plyometric training) Group B. (Second Package of Plyometric training) Group C. (Third Package of Plyometric training) and Group D. (Control Group) did not involve in any training. The selected student was evaluated through different tests before administering plyometric training. Plyometric training for a period of eight weeks in the direction of the researcher offered to the selected group of individuals. At the end of eight weeks, the post-test was taken.

Test Protocol

We used a modified test protocol. A Pilot Study was conducted for the purpose of finalizing and deciding up upon the intensity and duration of the various packages of a plyometric training program. The Pilot Study was conducted with twenty $(n=10)$ subjects to know the suitability of varied packages of plyometric training and to find out the difficulties and shortcomings of the study.

\section{Collection of Data}

Low, Medium and High Intensity of plyometric training were given as per the training schedule. The pre and post check records on the chosen criterion variables were accumulated by way of administering the test as in step with the standardized procedures before and after the eight weeks of the program.

\section{Experimental Procedure (Fig. 1.).}

Selection of the Tests

The study in hand examined the effects of assorted programs of plyometric training, (Low, Medium \& High intensity) on selected motor ability components such as Speed, Leg explosive power, and Muscular endurance among college male students. On the base of the present literature, the given test was conducted to gather associated information on the dependent variables which are given below (table 1).

\section{Criterion Measures}

1. Speed. The Speed of the subjects was measured by using a 50 yards' dash test. The measurement will be recorded $1 / 100$ of the seconds.

2. Leg Explosive Power. For measuring Leg Explosive Power, standing broad jump test was used and 
the unit of measurement were taken in meters.

3. Muscular Endurance. For measuring Muscular Endurance, sit ups test was used and the unit of measurement were taken in counts.

Equipment used

The following equipment was used during the conduction of the test:

1. Paint;

2. Table;

3. Rope;

4. Measuring tape.

\section{Result}

Effects of varied packages of plyometric training on speed

The analysis of covariance in the perspective of the effects of varied packages of plyometric training on the speed of the pre and post score of experimental groups and control group have been presented in the table mentioned below (table 2).

The above table depicts the pre-test mean score of speed regarding the effects of low intensity, medium intensity, high intensity, and control group. According to the analysed data, the mean scores were obtained 7.116, $7.114,7.116$, and 7.117 respectively for low intensity, medium intensity, high intensity, and control group.
According to the table, the obtained ' $\mathrm{f}$ ' ratio of 0.012 is less than the table value of 2.684

Likewise, the post-test results in terms of different groups like low intensity, medium intensity, high intensity, and control groups were recorded as 7.064, 7,046, 7.011, and 7.115. Similarly, the ' $f$ ' ratio was recorded greater than the table value $(12.982>2.684)$.

The adjusted mean scores of the post-test were noticed as 7.004, 7.047, 7.011, and 7.114 respectively for low intensity, medium intensity, high intensity, and control group. The analysed data have shown that the ' $\mathrm{f}$ ' value was found greater than the table value $(18.6726>2.684)$.

Based on the data analysis, the study revealed that there existed significant differences in the mean scores of adjusted post-test with reference to the effect of varied packages of plyometric training such as low intensity, medium intensity, and high intensity upon speed.

As there found a significant difference in the ' $\mathrm{f}$ ' ratio of adjusted post-test, therefore; the researcher applied Scheffe's test to analyze the paired mean differences (table 3).

The above table depicts the mean differences among different plyometric training groups including low intensity, medium intensity, high intensity, and control group of the participants upon speed. Accordingly,

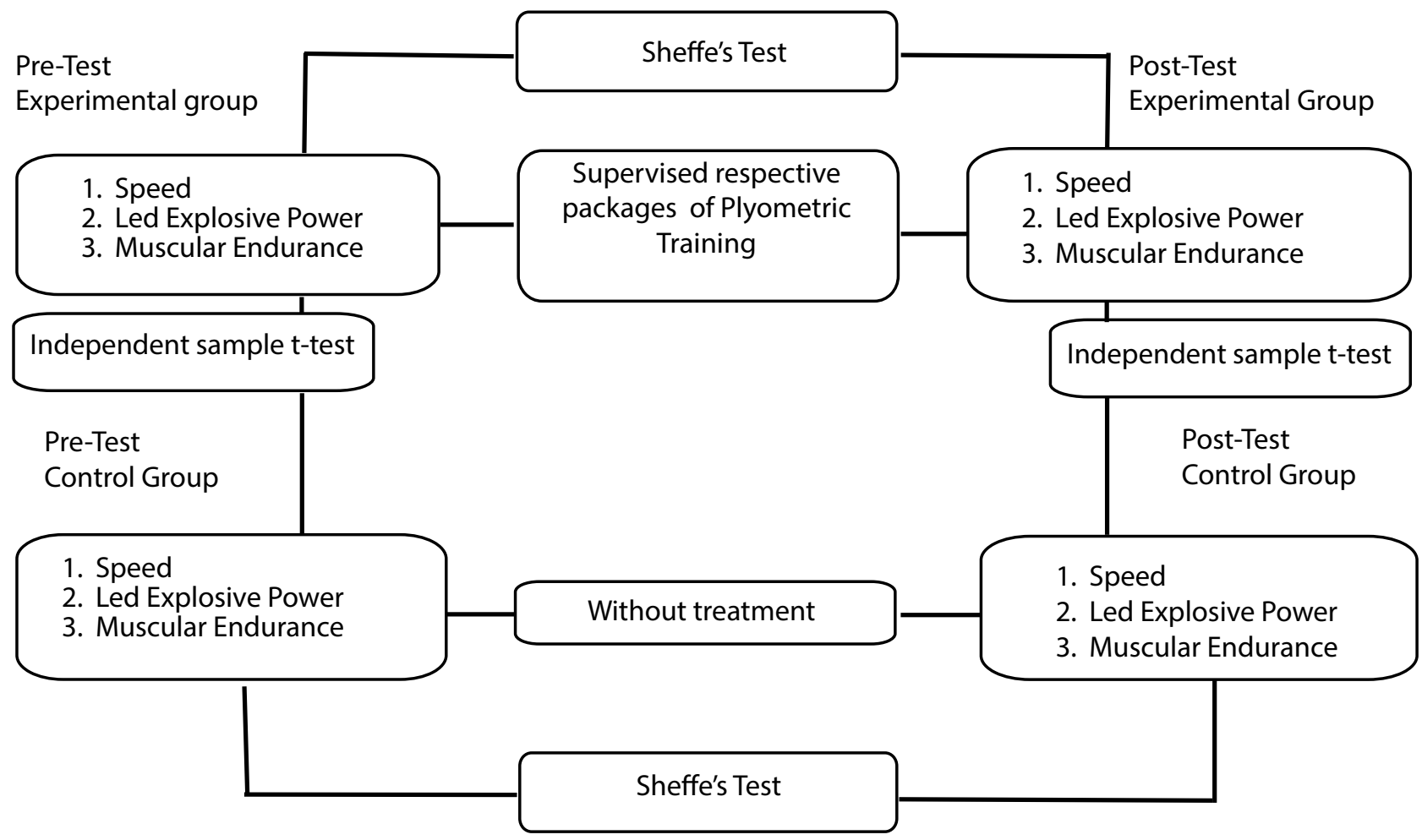

Fig. 1. Showing the experimental procedure used in the study

Table 1. Showing the description of selection of the tests

\begin{tabular}{lll}
\hline S. No & Variables & Tests applied \\
\hline 1 & Speed & 50 Yards Dash \\
2 & Leg Explosive Power & Standing Broad Jump \\
3 & Muscular Endurance & Sit-ups \\
\hline
\end{tabular}


the mean differences $0.056,0.052,0.665$, and 0.102 respectively for low intensity, medium intensity, high intensity, and control group were found greater than the required confidence interval value (CIV) at a confidence level of 0.05 . Therefore, it can be said that the above comparison was insignificant.

The table has shown the comparison between (LI) plyometric training group and (MI) plyometric training group and (MI) plyometric training group and (HI) plyometric training group. Accordingly, the results were found at 0.016 and 0.034 for the above comparison respectively. These scores were found lesser than the required confidence interval at a significant level $(0.016$, $0.034<0.04)$. Therefore, these two comparisons were found significant.

Effects of varied packages of plyometric training on leg explosive power

The analysis of covariance in the perspective of the effects of varied packages of plyometric training on leg explosive power of the pre and post score of experimental groups and control group have been presented in Table 4.

The above table represents the pre-test mean score of leg explosive power regarding the effects of low intensity, medium intensity, high intensity, and control group. According to the analysed data, the mean scores were obtained 2.223, 2.223, 2.229, and 2.228 respectively for low intensity, medium intensity, high intensity, and control group. According to the table, the obtained ' $\mathrm{f}$ ' ratio of 0.542 is greater than the table value of 2.684 .

Likewise, the post-test results in terms of different groups like low intensity, medium intensity, high intensity, and control groups were recorded as 2.247, 2.281, 2.323, and 2.229. Similarly, the 'f' ratio was recorded greater than the table value $(53.951>2.684)$.

The adjusted mean scores of the post-test were noticed as $2.260,2.284,2.320$, and 2.227 respectively for low intensity, medium intensity, high intensity, and control group. The analysed data have shown that the ' $f$ ' value was found greater than the table value $(128.915>2.684)$.

The study showed that there were significant differences in the mean scores of adjusted post-test with reference to the effect of varied packages of plyometric training upon leg explosive power of the selected participants.

As there found a significant difference in the ' $\mathrm{f}$ ' ratio of adjusted post-test, therefore; the researcher applied Scheffe's test to analyse the paired mean differences (table 5).

The above table depicts the mean differences among different plyometric training groups including low intensity, medium intensity, high intensity, and a control group of the participants upon speed. Accordingly, the mean differences $0.059,0.062,0.56$, and 0.092 respectively for low intensity, medium intensity, high intensity, and control group were found greater than the required confidence interval value (CIV) at a confidence level of 0.05 . Therefore, it can be said that the above comparison was insignificant.

The table has shown the comparison between (LI) plyometric training group and (MI) plyometric training group and (MI) plyometric training group and (HI) plyometric training group. Accordingly, the results were found at 0.023 and 0.035 for the above comparison respectively. These scores were found lesser than the required confidence interval at a significant level $(0.023$, $0.035<0.05)$. Therefore, these two comparisons were

Table 2. Showing the analysis of covariance of pre-test, post-test, and Adjusted post-test on the speed of experimental and control groups

\begin{tabular}{|c|c|c|c|c|c|c|}
\hline Test & LI & MI & $\mathrm{HI}$ & CG & Df & $O^{\prime} f^{\prime} R$ \\
\hline Pre-test Mean & 7.116 & 7.114 & 7.116 & 7.117 & & 0.012 \\
\hline Post-test Mean & 7.064 & 7.046 & 7.011 & 7.115 & $(3,57)$ & $12.982^{*}$ \\
\hline Adjusted Post-test Mean & 7.004 & 7.047 & 7.011 & 7.114 & & $18.6726^{*}$ \\
\hline
\end{tabular}

NOTE: *Significant at 0.05 level of confidence, $\mathrm{LI}=$ low intensity, $\mathrm{MI}=$ medium intensity, $\mathrm{HI}=$ high intensity, $\mathrm{CG}=\mathrm{control}$ group, $d f=$ degree of freedom \& OFR=obtained ' $f$ ' ratio.

Table 3. Cheffe's Test showing the differences between paired means of different groups on speed

\begin{tabular}{llllll}
\hline LI & MI & HI & CG & MD & CIV \\
\hline 7.056 & 7.039 & & & 0.016 & 0.04 \\
7.056 & & & $0.056^{*}$ & 0.04 \\
7.056 & & & 7.114 & $0.052^{*}$ & 0.04 \\
& & & 0.034 & 0.04 \\
& 7.039 & 7.011 & 7.114 & $0.665^{*}$ & 0.04 \\
& 7.039 & & 7.114 & $0.102^{*}$ & 0.04 \\
\hline
\end{tabular}

NOTE: *Significant at 0.05 level of confidence, LI= low intensity, $\mathrm{Ml}=$ medium intensity, $\mathrm{HI}=$ high intensity, $\mathrm{CG}=\mathrm{control}$ group, $\mathrm{MD}=$ mean differences, $\mathrm{CIV}=$ confidence interval value. 
found significant.

Effects of varied packages of plyometric training on muscular endurance

The analysis of covariance in the perspective of the effects of varied packages of plyometric training on muscular endurance of the pre and post score of experimental groups and control group have been presented in the table below (table 6).

The sketched table represents the pre-test mean score of muscular endurance regarding the effects of low intensity, medium intensity, high intensity, and control group. According to the analysed data, the mean scores were obtained 27.433, 27.522, 27.498, and 27.565 respectively for low intensity, medium intensity, high intensity, and control group. According to the table, the obtained ' $\mathrm{f}$ ' ratio of 0.030 is lesser than the table value of 2.684 required for significance at the 0.05 level.

Likewise, the post-test results in terms of different groups like low intensity, medium intensity, high intensity, and control groups were recorded as 30.798, 31.865, 33.423 , and 27.764. Similarly, the 'f' ratio was recorded greater than the table value $(35.10>2.684)$ required for significance at the 0.05 level.

The adjusted mean scores of the post-test were noticed as $30.858,31.845,33.438$, and 27.718 respectively for low intensity, medium intensity, high intensity, and control group. The analysed data have shown that the ' $\mathrm{f}$ ' value was found greater than the table value (97.288> 2.684).

The study showed significant differences in the mean scores of adjusted post-test with reference to the effect of varied packages of plyometric training upon the muscular endurance of the participants included in the study.

As there found a significant difference in the ' $\mathrm{f}$ ' ratio of adjusted post-test, therefore; the researcher applied Scheffe's test to analyse the paired mean differences (table 7).

The above table depicts the mean differences among different plyometric training groups including low intensity, medium intensity, high intensity, and a control group of the participants upon muscular endurance. Accordingly, the mean differences $0.985,2.578,3.137$, $1.591,4.124$, and 5.718 respectively for low intensity, medium intensity, high intensity, and control group were found greater than the required confidence interval value

Table 4. showing the analysis of covariance of pre-test, post-test and Adjusted post-test on leg explosive power of experimental and control groups

\begin{tabular}{|c|c|c|c|c|c|c|}
\hline Test & LI & MI & $\mathrm{HI}$ & CG & df & OFR \\
\hline Pre-test Mean & 2.223 & 2.223 & 2.229 & 2.228 & & 0.542 \\
\hline Post-test Mean & 2.247 & 2.281 & 2.323 & 2.229 & $(3,57)$ & 53.951 \\
\hline Adjusted Post-test Mean & 2.260 & 2.284 & 2.320 & 2.227 & & 128.915 \\
\hline
\end{tabular}

NOTE: *Significant at 0.05 level of confidence, $\mathrm{LI}=$ low intensity, $\mathrm{MI}=$ medium intensity, $\mathrm{HI}=$ high intensity, $\mathrm{CG}=\mathrm{control}$ group, $d f=$ degree of freedom \& OFR=obtained ' $f$ ' ratio.

Table 5. Scheffe's Test showing the differences between paired means of different groups on leg explosive power

\begin{tabular}{llllll}
\hline LI & MI & HI & CG & MD & CIV \\
\hline 2.252 & 2.276 & & & 0.023 & 0.014 \\
2.252 & & 2.32 & & $0.059^{*}$ & 0.014 \\
2.252 & & 2.227 & $0.062^{*}$ & 0.014 \\
& 2.276 & 2.32 & & 0.035 & 0.014 \\
& 2.276 & & 2.227 & $0.056^{*}$ & 0.014 \\
& & 2.32 & 2.227 & $0.092^{*}$ & 0.014 \\
\hline
\end{tabular}

NOTE: *Significant at 0.05 level of confidence, $\mathrm{LI}=$ low intensity, $\mathrm{MI}=$ medium intensity, $\mathrm{HI}=$ high intensity, $\mathrm{CG}=$ control group, $\mathrm{MD}=$ mean differences, $\mathrm{CIV}=$ confidence interval value.

Table 6. Showing the analysis of covariance of pre-test, post-test, and Adjusted post-test on muscular endurance of experimental and control groups

\begin{tabular}{|c|c|c|c|c|c|c|}
\hline Test & LI & MI & $\mathrm{HI}$ & CG & df & OFR \\
\hline Pre-test Mean & 27.433 & 27.522 & 27.498 & 27.565 & & 0.030 \\
\hline Post-test Mean & 30.798 & 31.865 & 33.423 & 27.764 & $(3,57)$ & $35.10 *$ \\
\hline Adjusted Post-test Mean & 30.858 & 31.845 & 33.438 & 27.718 & & $97.288^{*}$ \\
\hline
\end{tabular}

NOTE: *Significant at 0.05 level of confidence, $\mathrm{LI}=$ low intensity, $\mathrm{MI}=$ medium intensity, $\mathrm{HI}=$ high intensity, $\mathrm{CG}=$ control group, $d f=$ degree of freedom \& OFR=obtained ' $f$ ' ratio. 
(CIV) at a confidence level of 0.05 . Therefore, it can be said that the above comparison was insignificant.

\section{Discussion}

The study was conducted to assess the Effects of Varied Packages of Plyometric Training on Selected Motor Ability Components among undergraduate university students aging 20-23. The researcher collected data from the participants of four different groups such as low-intensity plyometric training, medium intensity plyometric training, high-intensity plyometric training, and control groups. The measurements were collected in perspectives of selected motor ability components including speed, leg explosive power, and muscular endurance.

In response to the first hypothesis that there would significant effects of varied packages of plyometric training on the speed of the college boys, the data revealed a significant difference in the mean score of pre and posttests of various plyometric training in respect of the speed of subjects. According to the analysed data, the mean scores were obtained 7.116, 7.114, 7.116, and 7.117 respectively for low intensity, medium intensity, high intensity, and control group. Likewise, the post-test results in terms of different groups like low intensity, medium intensity, high intensity, and control groups were recorded as 7.064, 7,046, 7.011, and 7.115.

The above significant statistical difference of the pre and post-tests in terms of average speed time showed a clear indication of the type of advantages of low intensity, medium intensity, high-intensity plyometric training aging 18-20 years. These findings are supported by the findings of [16-18]. It is evident by their findings that experimental groups had produced positive results after 6 weeks plyometric training program. Whereas, some research's' findings $[19,20]$ did not match the results of the present study

In respect of the hypothesis that there would significant effects of varied packages of plyometric training on leg explosive power of the college boys, the analysed data indicated, the mean scores were obtained 2.223, 2.223, 2.229 , and 2.228 respectively for low intensity, medium intensity, high intensity, and control group. Likewise, the post-test results in terms of different groups like low intensity, medium intensity, high intensity, and control groups were recorded as 2.247, 2.281, 2.323, and 2.229.

When compared to the mean score of different groups, the results exhibited significant statistical differences. The differences in the pre and post-tests showed a clear indication of the type of advantages of low intensity, medium intensity, high-intensity plyometric training holds for college boys. Similar results have been indicated by the researcher [21] as their findings revealed that concurrent endurance and circuit resistance training have produced positive effects on muscular strength and power development. Likewise, researchers [22] conducted a study and found that plyometric training has a positive effect on the perspective of the overall fitness and particularly the leg explosive power of the participants.

The hypotheses that there would significant effects of varied packages of plyometric training on muscular endurance of the college boys, the analysed inferences have shown significant mean differences in perspective of the effects of varied packages of plyometric training on muscular endurance of the pre and post score of experimental groups and control group.

These differences indicated that various plyometric training programs such as low intensity, medium intensity, high intensity have produced significant development in improving the muscular endurance of college male students. The findings of the present study are supported by the findings of [23] who found positive improvement of plyometric training on muscle functioning and athletic performance of college students. Marques et al. [24] indicated significant improvement in strength, endurance, and power performance in elite senior professional volleyball players after 6 weeks of plyometric training programs. Whereas, some other researchers [25] have found acute effects of plyometric exercise on maximum squat performance in male athletes.

\section{Main findings of the Study}

The researcher obtained the following findings after careful analysis of the collected measurements from the perspective of the effects of varied packages of plyometric training on selected motor ability components among undergraduate students aging 20-23 of Gomal University, Dera Ismail Khan, Khyber Pakhtunkhwa, Pakistan.

1. The results of the study revealed that there are

Table 7. Scheffe's Test showing the differences between paired means of different groups on muscular endurance

\begin{tabular}{llllll}
\hline LI & MI & HI & CG & MD & CIV \\
\hline 30.858 & 31.845 & & & 0.985 & 0.982 \\
30.858 & & 33.438 & & 2.578 & 0.982 \\
30.858 & & 27.718 & 3.137 & 0.982 \\
& & & & 1.591 & 0.982 \\
& 31.845 & 33.438 & 27.718 & 4.124 & 0.982 \\
& 31.845 & & 27.718 & 5.718 & 0.982 \\
\hline
\end{tabular}

NOTE: *Significant at 0.05 level of confidence, $\mathrm{LI}=$ low intensity, $\mathrm{MI}=$ medium intensity, $\mathrm{HI}=$ high intensity, $\mathrm{CG}=$ control group, $\mathrm{MD}=$ mean differences, $\mathrm{CIV}=$ confidence interval value. 
significant differences in the mean scores of adjusted post-test with reference to the effect of varied packages of plyometric training such as low intensity, medium intensity, and high intensity upon the speed of the subjects.

2. The study indicated that high-intensity plyometric training has produced a positive effect on the speed of the subjects.

3. Based on the analysed data, significant differences were noticed in the perspective of the adjusted mean scores of post-test for low intensity, medium intensity, high intensity, and control group. Therefore, it is found that plyometric training has produced a significant effect in empowering the leg explosive power among the subjects.

4. According to the analysed data, high-intensity plyometric training was noticed as superior then low and medium intensity plyometric training in the perspective of the effect on leg explosive power among the study participants.

5. Based on the significant differences in the adjusted mean scores of the post-test, the results indicated that plyometric has produced a positive effect on the muscular strength of the subjects.

6. The study has shown significant differences regarding the effect of varied packages of plyometric training upon muscular endurance as the results indicated that high-intensity plyometric training has produced a comparatively better effect upon the muscular endurance of the participants.

\section{Conclusion}

The results of the study revealed that various plyometric training programs have produced significantly the components of motor ability components such as speed, leg explosive power, and muscular endurance of the participants. The study has shown significant differences among different training packages including low-intensity plyometric training, medium intensity plyometric training, high-intensity plyometric training, and control groups with reference to their effects on speed, leg explosive power, and muscular endurance. Based on the data analyses, the results indicated that high-intensity plyometric training was noticed as superior then low and medium intensity plyometric training in the perspective of the effect of varied packages of plyometric on selected motor ability components among college students.

\section{Recommendations}

Keeping into consideration the results of the study, the researcher recommended that:

1. The results of the study revealed that highintensity plyometric training has produced a comparatively better effect on the research variables. Therefore, it is recommended that the coaches, trainers, and physical educationists may use high-intensity plyometric training to improve the components of motor ability components such as speed, power, and leg explosive power.

2. The researchers also recommend that the exercise protocol used in this study may help to adopt for the development and improvement of such components (Speed, Leg explosive power, and Muscle endurance) to get peak performance in sports.

\section{Conflicts of interest}

The authors declare no conflicts of interest.

\section{References}

1. Ade PA, Aghanim N, Arnaud M, Ashdown M, Aumont J, Baccigalupi C, wt al. Planck 2015 results-XIII. Cosmological parameters. Astronomy \& Astrophysics, 2016;594:A13.

2. Zatsiorsky VM, Kraemer WJ. Science and practice of strength training. Human Kinetics; 2006.

3. Hays K, Maynard I, Thomas O, Bawden M. Sources and types of confidence identified by world class sport performers. Journal of Applied Sport Psychology, 2007;19(4):434- 56. https://doi.org/10.1080/10413200701599173

4. MacNamara Á, Button A, Collins D. The role of psychological characteristics in facilitating the pathway to elite performance part 1: Identifying mental skills and behaviors. The Sport Psychologist, 2010;24(1):52- 73. https://doi.org/10.1123/tsp.24.1.52

5. Sedaghati P. The Effect of Selective Plyometric Exercises Using an Unstable Surface on the Movement Performance of Basketball Players. Annals of Applied Sport Science. 2018;6(3):15-22. https://doi.org/10.29252/aassjournal.6.3.15

6. Davies G, Riemann BL, Manske R. current Concepts of plyometric exercise. International Journal of Sports Physical Therapy, 2015;10:760-86.

7. Heggelund J, Fimland MS, Helgerud J, Hoff J. Maximal strength training improves work economy, rate of force development and maximal strength more than conventional strength training. European
Journal of Applied Physiology, 2013;113(6):1565-73. https://doi.org/10.1007/s00421-013-2586-y

8. Ebben WP, Simenz C, Jensen RL. Evaluation of plyometric intensity using electromyography. Journal of Strength and Conditioning Research, 2008; 22 (3): 861-868. https://doi.org/10.1519/JSC.0b013e31816a834b

9. Wang YC, Zhang N. Effects of plyometric training on soccer players. Experimental and Therapeutic Medicine. 2016;12(2):550-4. https://doi.org/10.3892/etm.2016.3419

10.El-Ashker S, Hassan A, Taiar R, Tilp M. Long jump training emphasizing plyometric exercises is more effective than traditional long jump training: A randomized controlled trial. Journal of Human Sport and Exercise. 2019;14(1):215-224. https://doi.org/10.14198/jhse.2019.141.18

11.Golzari A, Rahimi A, Meli MHN. Comparison of the effect of six weeks of strength and plyometric exercises on some of the kinematic parameters of the lower extremities in the impact on the foot of football player's girl of 20 to 25 years old. International Journal of Ecosystems and Ecology Science-Ijees. 2018;8(2):367-374.

12.Racil G, Jlid MC, Bouzid MS, Sioud R, Khalifa R, Amri $M$, et al. Effects of flexibility combined with plyometric exercises vs. isolated plyometric or flexibility mode in adolescent male hurdlers. Journal of Sports Medicine and Physical Fitness. 2020;60(1):45-52. https://doi.org/10.23736/s0022-4707.19.09906-7 
13.Stewart E, Kernozek T, Peng HT, Wallace B. Impact kinetics associated with four common bilateral plyometric exercises. Journal of Sports Medicine and Physical Fitness. 2019;59(4):575-580. https://doi.org/10.23736/s0022-4707.18.08359-7

14.Chu DA, Meyer GC. Plyometrics. Human kinetics; 2013.

15.Kraemer WJ, Häkkinen K. The Handbooks of Sports Medicine and Science: Strength Training for Sport. John Wiley \& Sons; 2008.

16.Faigenbaum AD, McFarland JE, Keiper FB, Tevlin W, Ratamess NA, Kang J, Hoffman JR. Effects of a shortterm plyometric and resistance training program on fitness performance in boys age 12 to 15 years. Journal of Sports Science \& Medicine. 2007;6(4):519.

17.Castagna C, Abt G, Manzi V, Annino G, Padua E, D'Ottavio S. Effect of recovery mode on repeated sprint ability in young basketball players. The Journal of Strength \& Conditioning Research, 2008;22(3):923-9. https://doi.org/10.1519/JSC.0b013e31816a4281

18.de Villarreal ES, González-Badillo JJ, Izquierdo $\mathrm{M}$. Low and moderate plyometric training frequency produces greater jumping and sprinting gains compared with high frequency. The Journal of Strength \& Conditioning Research, 2008;22(3):715-25. https://doi.org/10.1519/JSC.0b013e318163eade

19.Impellizzeri FM, Rampinini E, Castagna C, Martino F, Fiorini $\mathrm{S}$, Wisloff U. Effect of plyometric training on sand versus grass on muscle soreness and jumping and sprinting ability in soccer players. British Journal of Sports Medicine, 2008;42(1):42-6. https://doi.org/10.1136/bjsm.2007.038497

20.Kraemer WJ, Ratamess N, Fry AC, Triplett-McBride T, Koziris LP, Bauer JA, et al. Influence of resistance training volume and periodization on physiological and performance adaptations in collegiate women tennis players. The American Journal of Sports Medicine, 2000;28(5):626-33. https://doi.org/10.1177/03635465000280050201

21.Chtara M, Chaouachi A, Levin GT, Chaouachi M, Chamari K, Amri M, Laursen PB. Effect of concurrent endurance and circuit resistance training sequence on muscular strength and power development. The Journal of Strength \& Conditioning Research, 2008;22(4):1037-45. https://doi.org/10.1519/JSC.0b013e31816a4419

22.Diallo O, Dore E, Duche P, Van Praagh E. Effects of plyometric training followed by a reduced training programme on physical performance in prepubescent soccer players. Journal of Sports Medicine and Physical Fitness, 2001;41(3):342.

23.Markovic G, Jukic I, Milanovic D, Metikos D. Effects of sprint and plyometric training on muscle function and athletic performance. The Journal of Strength \& Conditioning Research, 2007;21(2):543-9. https://doi.org/10.1519/00124278-200705000-00044

24.Marques MC, Van Den Tillaar R, Vescovi JD, GonzálezBadillo JJ. Changes in strength and power performance in elite senior female professional volleyball players during the in-season: a case study. The Journal of Strength \& Conditioning Research, 2008;22(4):1147-55. https://doi.org/10.1519/JSC.0b013e31816a42d0

25. Masamoto N, Larson R, Gates $\mathrm{T}$, Faigenbaum A. Acute effects of plyometric exercise on maximum squat performance in male athletes. The Journal of Strength \& Conditioning Research, 2003;17(1):68-71. https://doi.org/10.1519/00124278-200302000-00011

\section{Information about the authors:}

Wasim Khan; Lecturer; https://orcid.org/0000-0002-1888-2975; wasimkhansspe@gu.edu.pk; Department of Sports Sciences and Physical Education, Gomal University, D.I.Khan; Dera Ismail Khan, Pakistan.

Tasleem Arif; Assistant Professor; https://orcid.org/0000-0002-0718-5330; Tasleemarif12345@gmail.com; Department of Sports Sciences and Physical Education, Sarhad University of Information Technology; Peshawar, Pakistan.

Khushdil K. Muhammad; https://orcid.org/0000-0001-9806-9855; happyheartsspe@gmail.com; Department of Sports Sciences and Physical Education, Gomal University, D.I.Khan; Dera Ismail Khan, Pakistan.

Sardar N. Sohail; (Corresponding author); https://orcid.org/0000-0003-3786-7890; balochbk@gmail.com; Department of Sports Sciences and Physical Education, Gomal University, D.I.Khan; Dera Ismail Khan,Pakistan.

Irina V. Kriventsova; http://orcid.org/0000-0001-6931-3978; kriventsova.ira@ukr.net; H.S. Skovoroda Kharkiv National Pedagogical University; Kharkiv, Ukraine.

\section{Cite this article as:}

Khan W, Arif T, Muhammad KK, Sohail SN, Kriventsova IV. Effects of varied packages of plyometric training on selected motor ability components among university students. Physical Education of Students, 2020;24(5):278-285. https://doi.org/10.15561/20755279.2020.0504

This is an Open Access article distributed under the terms of the Creative Commons Attribution License, which permits unrestricted use, distribution, and reproduction in any medium, provided the original work is properly cited http://creativecommons.org/licenses/by/4.0/deed.en

Received: 15.08 .2020

Accepted: 03.11.2020; Published: 30.10 .2020 